\title{
Protein network analysis reveals selectively vulnerable regions and biological processes in FTD
}

Luke W. Bonham, BS, Natasha Z.R. Steele, MPH, Celeste M. Karch, PhD, Claudia Manzoni, PhD, Ethan G. Geier, PhD, Natalie Wen, Aaron Ofori-Kuragu, Parastoo Momeni, PhD, John Hardy, PhD, Zachary A. Miller, MD, Christopher P. Hess, MD, PhD, Patrick Lewis, PhD, Bruce L. Miller, MD, William W. Seeley, MD, Sergio E. Baranzini, PhD, Rahul S. Desikan, MD PhD, Raffaele Ferrari, PhD, and Jennifer S. Yokoyama, PhD, on behalf of the International FTD-Genomics Consortium (IFGC)

Neurol Genet 2018;4:e266. doi:10.1212/NXG.0000000000000266

\section{Abstract}

\section{Objective}

The neuroanatomical profile of behavioral variant frontotemporal dementia (bvFTD) suggests a common biological etiology of disease despite disparate pathologic causes; we investigated the genetic underpinnings of this selective regional vulnerability to identify new risk factors for bvFTD.

\section{Methods}

We used recently developed analytical techniques designed to address the limitations of genome-wide association studies to generate a protein interaction network of 63 bvFTD risk genes. We characterized this network using gene expression data from healthy and diseased human brain tissue, evaluating regional network expression patterns across the lifespan as well as the cell types and biological processes most affected in bvFTD.

\section{Results}

We found that bvFTD network genes show enriched expression across the human lifespan in vulnerable neuronal populations, are implicated in cell signaling, cell cycle, immune function, and development, and are differentially expressed in pathologically confirmed frontotemporal lobar degeneration cases. Five of the genes highlighted by our differential expression analyses, BAIAP2, ERBB3, POU2F2, SMARCA2, and CDC37, appear to be novel bvFTD risk loci.

\section{Conclusions}

Our findings suggest that the cumulative burden of common genetic variation in an interacting protein network expressed in specific brain regions across the lifespan may influence susceptibility to bvFTD.

\author{
Correspondence \\ Dr. Yokoyama \\ jennifer.yokoyama@ucsf.edu
}

From the Department of Neurology (L.W.B., N.Z.R.S., E.G.G., Z.A.M., B.L.M., W.W.S., J.S.Y.), Memory and Aging Center, University of California, San Francisco; Department of Psychiatry (C.M.K., N.W., A.O.-K.), Washington University, St. Louis, MO; School of Pharmacy (C.M., P.L.), University of Reading, Reading, UK; Laboratory of Neurogenetics (P.M.), Texas Tech University Health Science Center, Lubbock; Department of Molecular Neuroscience (C.M., J.H., P.L., R.F.), UCL Institute of Neurology, London, UK; Department of Radiology and Biomedical Imaging, Neuroradiology Section (C.P.H., R.S.D.), University of California, San Francisco; and Department of Neurology (S.E.B.), University of California, San Francisco. Funding information and disclosures are provided at the end of the article. Full disclosure form information provided by the authors is available with the full text of this article at Neurology.org/NG.

The Article Processing Charge was funded by the authors.

This is an open access article distributed under the terms of the Creative Commons Attribution-NonCommercial-NoDerivatives License 4.0 (CC BY-NC-ND), which permits downloading and sharing the work provided it is properly cited. The work cannot be changed in any way or used commercially without permission from the journal. 


\section{Glossary}

$\mathbf{A D}=$ Alzheimer disease; $\mathbf{B P}=$ biological process; CSEA = cell-type SEA; EGFR $=$ epidermal growth factor; FDR = falsediscovery rate; bvFTD = behavioral variant frontotemporal dementia; FTLD = frontotemporal lobar degeneration; GO = gene ontology; GWAS = genome-wide association study; IFGC = International FTD-Genomics Consortium; MAPK = mitogenactivated protein kinase; PD = Parkinson disease; PDGF = platelet-derived growth factor; PINBPA = protein interaction network-based pathway analysis; SEA = specific enrichment analysis; VEN = Von Economo neuron; W-PPI-NA = weighted protein-protein interaction network analysis.

Although defined by a clear clinical syndrome, behavioral variant frontotemporal dementia (bvFTD) is the most pathologically diverse form of frontotemporal lobar degeneration (FTLD). Despite variable pathology, we and others have shown that a shared, selectively vulnerable brain network, composed of disparate brain regions functionally connected throughout the lifespan, degenerates in bvFTD. ${ }^{1}$ The fact that different protein pathologies converge on a relatively consistent set of neuroanatomical regions suggests intrinsic molecular properties may predispose this network to disease. Nevertheless, despite extensive advances in our ability to clinically and pathologically diagnose bvFTD, little is known about the protein networks ("nexopathies") that drive the biological processes (BPs) underlying this selective vulnerability. ${ }^{2,3}$

New techniques enable evaluation of experimentally determined protein networks in disease by aggregating single-nucleotide polymorphism (SNP)-level risk metrics across an entire gene. This technique increases statistical power, overcomes locus heterogeneity likely to occur in clinical populations, and allows for better detection of multiple variants contributing to polygenic disease risk. ${ }^{4}$ Combining this information with existing protein interaction data has revealed new genetic risk loci and helped unravel the pathophysiology of complex diseases like multiple sclerosis. $^{5}$

In this study, we first generated networks of genes underlying bvFTD risk to identify common pathophysiologic processes underlying disease biology. Second, based on prior studies showing that the brain network affected in bvFTD is present and functioning throughout life, ${ }^{6}$ we evaluated spatial and temporal risk gene expression patterns in human brain across the lifespan. Finally, we sought to validate risk network genes using brain tissue from patients pathologically diagnosed with FTLD.

\section{Methods}

\section{Standard protocol approvals, registrations, and patient consents}

Written informed consent was obtained from all participants or their guardians at the site of sample collection, and relevant institutional review boards approved all aspects of the study.

\section{Genome-wide association study study participants}

This study used SNP level metadata from phase 1 FTDGWAS data from the International FTD-Genomics
Consortium (IFGC), which was composed of 1,377 bvFTD cases and 4,308 controls with genotypes or imputed data at $6,026,384$ SNPs. Raw genetic data for each participant was not available for analysis at the inception of this study. Cases and controls within the cohort were diagnosed according to published criteria for bvFTD $^{7}$ by a trained neurologist or pathologic examination. ${ }^{8}$

\section{Gene network generation}

We calculated gene-level significance values using Versatile Gene-based Association Study (VEGAS) ${ }^{9}$ and summary data from a recent bvFTD genome-wide association study (GWAS). ${ }^{8}$ VEGAS assigns SNPs to their respective autosomal genes using their position on the University of California, Santa Cruz Genome Browser. To capture the effects of regulatory regions and SNPs in linkage disequilibrium, ${ }^{10}$ gene boundaries were defined as $50 \mathrm{~kb}$ beyond the $5^{\prime}$ and $3^{\prime}$ untranslated regions of each gene. Empirical $p$-values for each gene were calculated using Monte-Carlo simulations. ${ }^{5,9}$ Association blocks were defined as groups of sequential genes with $p<0.05$.

We used protein interaction network-based pathway analysis (PINBPA) to compute first-order interactions by filtering a reference network containing 8,960 proteins and 27,724 interactions so that only the genes (and their protein products) with VEGAS $p$ $<0.05$ were retained as significant. We evaluated network strength using simulations, which assigned $p$-values to genes at random from the parent network to create a simulated distribution of similarly sized networks. The empirical bvFTD network's characteristics were compared against the simulated networks.

To increase resolution on the candidate proteins isolated by the PINBPA method, we generated a second independent network with recently developed weighted protein-protein interaction network analysis (W-PPI-NA) ${ }^{11}$ using the 63 bvFTD genes prioritized by PINBPA as seeds. Of note, the genes prioritized by the PINBPA analysis (CALM2 and $C A L M 3)$ were combined into one unique entry, CALM1, through this step. We removed TrEMBL, non-protein interactors (e.g., chemicals), obsolete Entrez, and Entrez matching to multiple Swiss-Prot identifiers.

\section{Profiling of gene expression during development and across the human lifespan}

To assess whether genes from the PINBPA networks showed enriched expression in human brain tissues of all ages and life stages, we used the $\mathrm{R}$ package ABAEnrichment and specific 
enrichment analysis (SEA). ABAEnrichment performs ontology gene set enrichment analyses for 26 brain regions ranging in age from 8 postconception weeks to 40 years old from the BrainSpan data set distributed by the Allen Brain Institute. Forty-five percent of participants were Caucasian, 33\% were African American, 10\% were Hispanic, 5\% were mixed Caucasian/African American, and 5\% had no ethnicity information available. All participants were screened for neurologic conditions and for large-scale chromosomal abnormalities. Samples were grouped by age into 5 groups: prenatal (all prenatal stages; $n=20)$, infant $(0-2$ years; $n=6)$, child ( $3-11$ years; $n=6)$, adolescent $(12-19$ years; $n=4)$, and adult (older than 19 years; $\mathrm{n}=6$ ). Additional demographic data are provided in table e-1 (links.lww.com/NXG/A72). All genes evaluated in enrichment analyses were expressed above the 10th percentile when ranked by expression. SEA allows for expression testing across 6 brain regions and 10 different developmental periods. Fisher's exact test was used to assess statistical enrichment, and false-discovery rate (FDR) correction was applied.

\section{Cell-type-specific gene expression profiling}

We used 2 RNA expression data sets examining several cell types commonly found in the CNS, one to conduct descriptive representations of the cells that most highly express our genes of interest and the other to specifically test for enrichment.

The first data set used gene expression from human temporal lobe samples. ${ }^{12}$ For each gene implicated in the bvFTD network, we queried the database and recorded the cell type (fetal astrocytes, mature astrocytes, neurons, oligodendrocytes, microglia/macrophages, and endothelial cells) that most highly expressed the gene of interest. The data set represents expression across the human lifespan (18 postconception weeks $[\mathrm{pcw}]$ for fetal samples and 8-63 years old for non-fetal samples). ${ }^{12}$

The second data set used RNAseq data from the BrainSpan atlas to characterize cell-specific expression patterns. Enrichment for specific cell types was tested using cell-type SEA (CSEA), ${ }^{13}$ which employs expression cutoffs and tests for cell-type-specific enrichment (CSEA employs methodology similar to SEA). Cell types are determined using wellvalidated markers, ${ }^{14}$ and enrichment is tested using Fisher's exact test with FDR correction.

\section{Biological pathways and processes analysis}

We classified the biological function of bvFTD network genes using PANTHER (pantherdb.org) and Reactome (reactome. org) to reduce the likelihood of spurious findings from any one source. Statistical tests for overrepresentation with Bonferroni correction were performed using the PANTHER pathways annotation and Gene Ontology (GO) BPs databases. We applied functional annotation analysis to the network built using the 62 PINBPA-prioritized genes as seeds by performing GO BP enrichment analyses through g:Profiler
(g:GOSt, biit.cs.ut.ee/gprofiler/ ${ }^{15}$ ) (62 genes were used because $C A L M 2$ and $C A L M 3$ were combined into one entry as previously described). A Fisher's one-tailed test was used to assess enrichment; the set counts and sizes threshold was applied as a multiple test correction; statistical domain size was only annotated genes; and no hierarchical filtering was included. We then grouped enriched GO-BP terms into custom-made "semantic classes." We removed general, thus negligible, semantic classes, such as general, metabolism, enzymes, protein modification, and physiology. Semantic classes were further grouped by similarity in more general classes called functional blocks.

\section{Gene expression in pathologically confirmed FTLD cases}

We analyzed gene expression data from 2 cohorts of pathologically confirmed FTLD along with Alzheimer disease (AD) and Parkinson disease (PD) cases compared with normal older adult controls. The first FTLD cohort contained 10 individuals with pathologically confirmed sporadic FTLD, 7 individuals with pathologically confirmed FTLD due to GRN mutations, and 11 pathologically confirmed controls (GSE13162). The second contained 6 FTLD cases with primarily tau pathology (Constantinides group A), 6 FTLD cases with primarily temporal atrophy and minimal tau pathology (Constantinides group $\mathrm{C} 1$ ), and 5 normal controls (E-MEXP-2280). The $\mathrm{AD}$ cohort included temporal cortex samples from $84 \mathrm{AD}$ and 80 control brains (syn5550404). ${ }^{16}$ The PD cohort included substantia nigra samples from $22 \mathrm{PD}$ and 23 control brains (GSE7621). ${ }^{17}$ In linear regression analyses, we analyzed FTLD cases together in a combined analysis and then performed separate subgroup analyses. Following this, we analyzed the $\mathrm{AD}$ and PD groups separately. In all analyses, we covaried for age, sex, and postmortem interval.

\section{Results}

\section{bvFTD GWAS data reveals a large protein interaction network driven by risk-associated alleles}

Using gene-based $p$-values for 17,463 genes derived from the bvFTD GWAS cohort, we identified 475 association blocks containing a total of 1,104 genes. We next generated PINBPA networks for the genes implicated in bvFTD. The bvFTD network contained 63 nodes and 72 edges. Permutation testing revealed that the bvFTD gene network was within the top 10th percentile for nodes and edges as compared with a sample of 1,000 randomly generated networks (figure 1 and table e-2, links.lww.com/NXG/A73).

We then sought to analyze the topological details of the 63 PINBPA-prioritized genes by generating protein interaction networks with our W-PPI-NA to highlight key functional players within the identified gene set. After filtering and scoring the protein network, the result was composed of 1,913 nodes and 3,212 edges, where all but one node, PBX2, were 




The bvFTD PINBPA network is shown. Nodes are color coded according to their gene-based $p$-value, with warmer colors indicating lower $p$-values and cooler colors representing $p$-values closer to 0.05 . Node size represents closeness centrality, a measure of a node's nearness to other nodes within a network. Edge thickness represents edge betweenness, a measure of the number of paths that go through an edge in a network. interconnected (figure 2, A). We identified the interinteractome hubs (IIHs; $\mathrm{n}=10$ ) - the proteins characterized by the highest connection degree distribution (figure 2, B and C) - and we used them to define the core of the network with the highest interconnectivity (figure 2, D). By comparing the core of the network with randomly sampled parts of the network, we verified that the IIHs-driven network is the most densely connected. The core of the network was made of 52 nodes (10 IIHs and their interactors) and 121 edges; these were strongly interconnected (average number of neighbors = $4.5)$, representing the proteins that keep the cohesion of $>16 \%$ of the initial seeds $(n=63$; figure $2, C)$.

\section{bvFTD network genes show enriched expression in bvFTD-relevant brain regions across the lifespan}

We next tested whether genes within the bvFTD network showed enriched or specific expression in distinct brain regions of healthy individuals using ABAEnrichment. Hypergeometric tests revealed enriched expression for our bvFTD network genes in neuroanatomical regions affected in bvFTD, including the dorsolateral prefrontal cortex, frontal cortex, and temporal cortex in most age groups (family-wise error corrected $p<0.05$ for each region, figure 3, A-D and table e-3, links.lww.com/NXG/A74).

Our $A B A E n$ richment analyses suggested that enrichment was most common during early life (table e-3, links.lww.com/ NXG/A74). However, they did not provide information on the role of gene expression within the early life stages when gene expression patterns can vary temporally and influence neurodevelopmental processes. ${ }^{18}$ Given this, we performed exploratory analyses using SEA and found that there were several nominally associated regions of gene expression enrichment concentrated within the fetal period. At a specificity index probability level of 0.05 , the amygdala (late fetal; $p=$ 0.004), thalamus (early fetal; $p=0.006$ ), hippocampus (late fetal; $p=0.007$ ), and cortex (mid-late fetal; $p=0.014$ ) showed nominal enrichment levels but did not withstand FDR correction (table e-4, links.lww.com/NXG/A75).

\section{bvFTD network genes are most highly expressed in fetal astrocytes, mature astrocytes, microglia, and cortical layer $5 b$ neurons}

Analysis of whole transcriptome data from specific cell types isolated from human brain tissue ${ }^{12,19}$ revealed that the bvFTD network genes clustered into 3 main brain cell groupings. The most commonly observed cell type was fetal astrocytes (37\%), followed closely by neurons (35\%), and microglia (20\%). bvFTD network genes were present at a lower frequency in mature astrocytes (5\%), oligodendrocytes (5\%), and endothelial cells (5\%) (figure e-1, links.lww.com/NXG/A79). Network genes represented only 3 of 100 and 11 of 500 of the top-expressed genes in each cell type, suggesting that the cell type enrichment was specific to bvFTD and not a function of detecting genes that were most highly expressed in these cell types. IL 2 and SLA2 were not expressed at a level that allowed for reliable cell type determination.

Given our findings in the cell-type-specific expression data set, we next used CSEA to test for enrichment of our bvFTD network genes in specific cell types and populations. The 

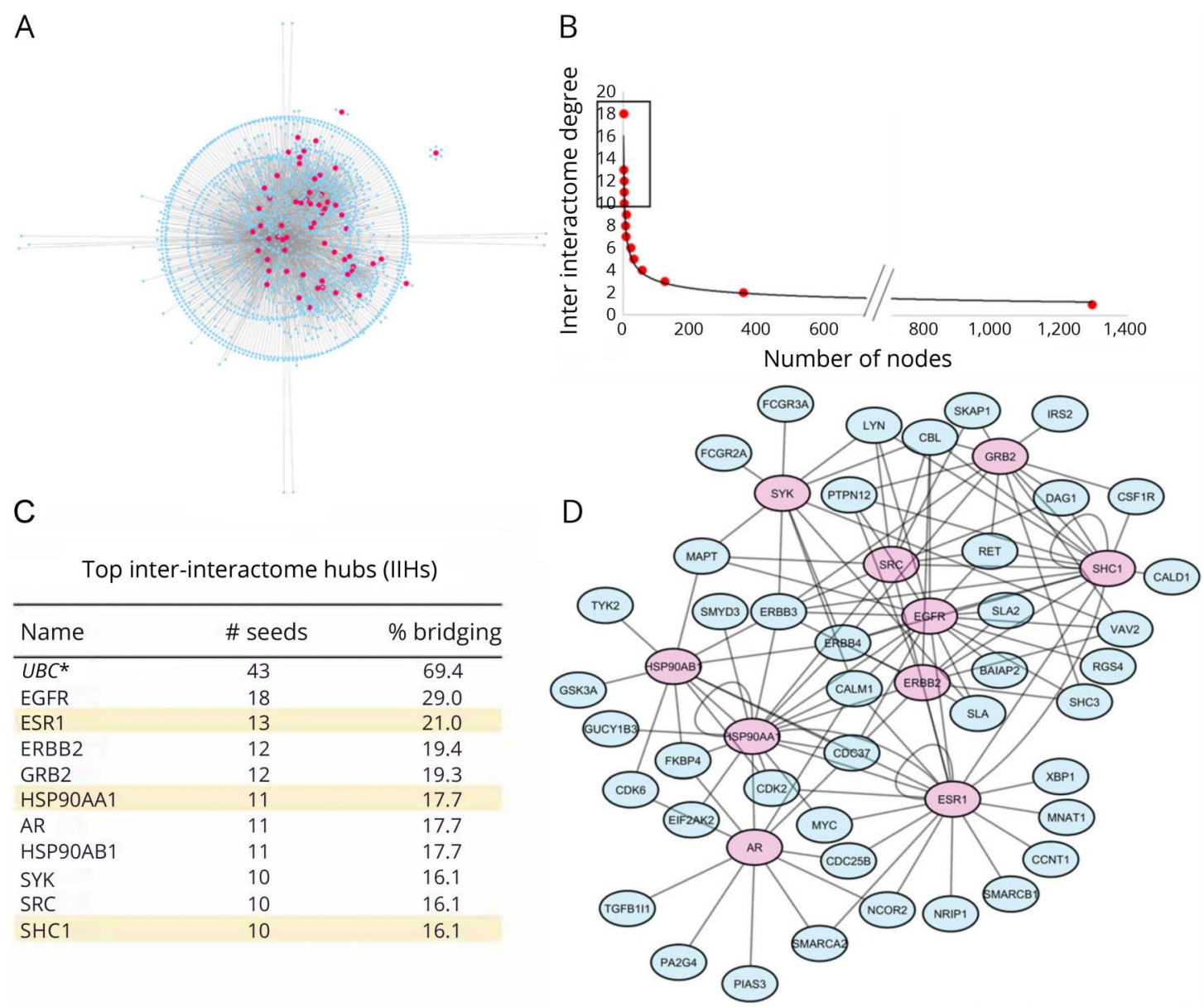

(A) Protein network built through the W-PPI-NA pipeline around the 63 genes prioritized by the PINBPA protocol. The seeds are depicted in pink and their interactors in blue. (B) Inter-interactome degree distribution curve reporting the number of nodes ( $\mathrm{x}$-axis) able to bridge an $\mathrm{N}$ number of seeds ( $\mathrm{y}$-axis). The $\mathrm{IIHs}$ are the nodes marked by the rectangle. (C) List of IIHs reporting the number of seeds that they bridge and associated \%. *UBC has been reported yet ignored as it is likely a false positive (as it may indicate unspecific binding of ubiquitin to proteins tagged for degradation). (D) Core of the network around the $\| \mathrm{Hs}$, which are depicted in pink.

bvFTD network genes demonstrated enriched expression in layer 5 b neuronal cells $(p=0.038$; figure e-1, links.lww.com/ NXG/A79 and table e-5, links.lww.com/NXG/A76); however, this association did not withstand FDR correction. Von Economo neurons (VENs) and fork cells, which are among the earliest cells to degenerate in bvFTD, are located within layer $5 b^{20}$

\section{Ontological analyses reveal overrepresentation of immune signaling in bvFTD risk genes}

Functional (ontological) characterization of the 63 bvFTD network genes indicated overrepresentation of immunemediated pathways, cell signaling, cell cycle, and development (table 1). Reactome analysis indicated the greatest degree of overrepresentation in pathways known to be involved with microglia-initiated inflammatory responses, such as epidermal growth factor (EGFR) signaling, mitogen-activated protein kinases (MAPKs), and pro-inflammatory cytokines (IL-3, IL-5, granulocyte- macrophage colony-stimulating factor [GM-CSF]) (table e-6, links.lww.com/NXG/A77). PANTHER analysis found similar overrepresentation for interleukin signaling pathways, EGFR signaling, and platelet-derived growth factor (PDGF) signaling.

We evaluated additional GO BPs via g:Profiler for the second protein network built by W-PPI-NA and focused on the interactomes of the 63 genes prioritized through the PINBPA protocol. This first functional enrichment was followed by a second iteration performed only on the core of the network-i.e., defined by the IIHs and their interactors-thus containing the most densely connected proteins. Functional annotation of the latter indicated a list of semantic classes that were a subset of the former: of interest, the subset terms (percentage of retention $>15 \%$ ) pointed to the following functional blocks: (1) "development"; (2) "motility"; (3) "protein modification"; and (4) "cell signaling" (figure e-2, links.lww.com/NXG/A80). These appeared as the common functions characterizing the part of the protein network with 


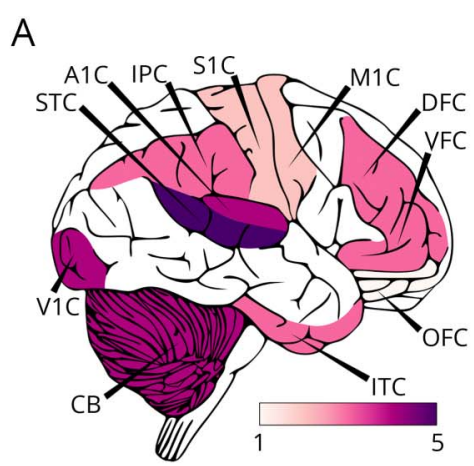



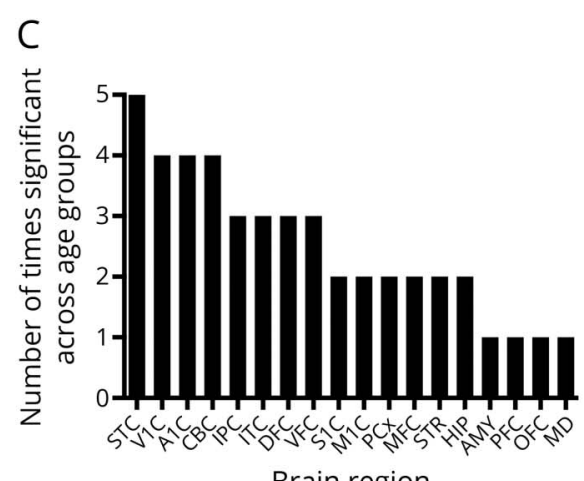

Brain region

D



For each of the 5 age groups used in the ABAEnrichment analyses, we counted the number of times each of the 26 available brain regions showed enrichment of the bvFTD network genes. The superior temporal cortex was the most common region of enriched expression with 5 observations (i.e., in every age grouping). Generally, the FTD cohort showed enriched expression in both frontal (DFC, VFC, M1C, PFC, OFC) and temporal (A1C, ITC, STC, MFC) regions. (A and B) The number of times each region was associated is illustrated on a model brain. Brain regions were mapped onto the illustration using information provided in Bahl et al. 2017. When regional overlap was detected (e.g., IPC is contained within PCx or DFC; VFC and OFC are contained within PFC), the more specific region(s) was chosen for presentation. (C) A graphical depiction of the data shown in (A and B). The number of times each brain region was associated from the 5 age groupings is shown. (D) Detailed results are shown in a table format with age groupings as rows and brain regions as columns. Regions shaded in black were statistically associated while unshaded regions were not. $\mathrm{A} 1 \mathrm{C}=$ primary auditory cortex; $\mathrm{AMY}=$ amygdaloid complex; $\mathrm{CN}=\mathrm{cerebral}$ nuclei; $\mathrm{CB}=$ cerebellum; CBC = cerebellar cortex; DFC = dorsolateral prefrontal cortex; HIP = hippocampus; IPC = posteroventral (inferior) parietal cortex; ITC = inferolateral temporal cortex; M1C = primary motor cortex; MFC = anterior (rostral) cingulate (medial prefrontal) cortex; OFC = orbital frontal cortex; $\mathrm{PC}=$ parietal neocortex; PFC = prefrontal cortex; S1C = primary somatosensory cortex; STC = posterior (caudal) superior temporal cortex; STR = striatum; TCX = temporal neocortex; THA = thalamus; $\mathrm{V} 1 \mathrm{C}=$ primary visual cortex; VFC = ventrolateral prefrontal cortex.

strongest cohesion among the initial seeds. In particular, the functional block "development" contained semantic classes referring to cell differentiation and proliferation as well as glial and neuronal cell development, while the functional block "cell signaling" contained semantic classes referring to the previously mentioned MAPK, PDGF, and immune-specific signaling in addition to terms related to $\mathrm{Fc}$ (typically relevant for immune cells), ERBB (relevant for both developmental and immune processes), growth factors, and hormone-based signaling events. These findings confirmed the PANTHER and Reactome results, using a completely independent approach.

\section{bvFTD network genes are dysregulated in postmortem brain tissue}

To examine whether the risk-associated genes identified by the network analysis are differentially expressed in human disease, we assessed the expression patterns of our bvFTD genes in postmortem samples from 2 pathologically confirmed cohorts of FTLD cases along with $\mathrm{AD}^{16}$ and $\mathrm{PD}^{17}$ cases compared with pathology-free controls. In the first FTLD cohort, GSE13162, 61 bvFTD genes had expression data available. In the second FTLD cohort, E-MEXP-2280, there were 58 bvFTD genes with expression data available. Because the 2 data sets represent a mix of sporadic and autosomal dominant (GRN) postmortem cases (GSD13162) or sporadic cases with tau and non-tau pathology (E-MEXP2280), we analyzed data in aggregate and by gene status or pathologic subtype (table e-7, links.lww.com/NXG/A78). In GSE13162, 19 bvFTD genes were differentially expressed between cases vs controls $\left(\mathrm{P}_{\mathrm{FDR}}<0.05\right)$. In E-MEXP-2280, 26 bvFTD genes were differentially expressed $\left(\mathrm{P}_{\mathrm{FDR}}<0.05\right)$. Of these top genes, 9 (BALAP2, CALD1, CDC37, ERBB3, GSK3A, MAP3K5, POU2F2, SMARCA2, and TGFB1|1) showed dysregulation in both cohorts (table 2 and table e-7). Several of these genes appear to be novel risk factors for bvFTD (table 2). In AD cases, 7 of 9 bvFTD network genes were differentially expressed (table 2). In contrast, 0 of 9 network genes were differentially expressed in PD cases (table 2).

\section{Discussion}

We identified a network of interacting bvFTD risk genes that demonstrate enriched expression in bvFTD-affected brain regions and cell types across the human lifespan. Differential expression analyses in pathologically confirmed cases of FTLD and controls showed that many of our network genes were dysregulated in pathologically confirmed FTLD, and 5 potentially novel bvFTD risk genes showed altered expression 
Table 1 Pathway analysis in bvFTD network genes

\begin{tabular}{|c|c|c|c|c|c|c|}
\hline $\begin{array}{l}\text { Biological } \\
\text { pathway }\end{array}$ & Pathway & $\begin{array}{l}\text { No. of genes } \\
\text { reference, } \\
\text { candidate } \\
\text { data set }\end{array}$ & Candidate genes mapped & $\begin{array}{l}\text { Fold } \\
\text { enriched }\end{array}$ & $p$ Value & Database \\
\hline \multicolumn{7}{|l|}{$\begin{array}{l}\text { Immune } \\
\text { system }\end{array}$} \\
\hline & Interleukin signaling pathway & 98,5 & IL-2, MYC, SLA2, SHC1, IRS2 & 17.26 & $1.83 \times 10^{-3}$ & PANTHER \\
\hline & Interleukin 3, 5, and GM-CSF & 250,8 & IL-2, RET, GDNF, SHC1, SHC3, IRS2, LYN, CBL & 10.82 & $1.38 \times 10^{-3}$ & Reactome \\
\hline & $\begin{array}{l}\text { Fc gamma receptor } \\
\text { phagocytosis }\end{array}$ & 90,5 & FCGR2A, HSP90AA1, BAIAP2, FCGR3A, VAV2 & 18.79 & 0.01 & Reactome \\
\hline & $\begin{array}{l}\text { GP VI mediated activation } \\
\text { cascade }\end{array}$ & 55,4 & $I L-2, S H C 1, L Y N, V A V 2$ & 24.60 & 0.04 & Reactome \\
\hline \multicolumn{7}{|c|}{ Cell signaling } \\
\hline & EGF receptor signaling pathway & 139,6 & $S H C 1, S H C 3, C B L, E R B B 4, E R B B 3, M A P 3 K 5$ & 11.61 & $5.99 \times 10^{-4}$ & PANTHER \\
\hline & & 14,4 & $S H C 1, C B L, C D C 37, H S P 90 A A 1$ & 96.65 & $1.19 \times 10^{-4}$ & Reactome \\
\hline & ERBB2 & 43,4 & CDC37, HSP9OAA1, SHC1, PTPN12 & 31.47 & 0.02 & Reactome \\
\hline & ERBB4 & 315,8 & IL2, RET, ESR1, GDNF, SHC1, SHC3, IRS2, GSK3A & 8.59 & $7.55 \times 10^{-3}$ & Reactome \\
\hline & VEGF signaling & 307,9 & $\begin{array}{l}\text { IL2, RET, GDNF, SHC1, SHC3, IRS2, HSP9OAA1, } \\
\text { BAIAP2, VAV2 }\end{array}$ & 9.92 & $5.52 \times 10^{-4}$ & Reactome \\
\hline & MAPK signaling & 229,7 & IL2, RET, TYK2, GDNF, SHC1, SHC3, IRS2 & 10.34 & $9.55 \times 10^{-3}$ & Reactome \\
\hline & $\begin{array}{l}\text { FCERI-mediated MAPK } \\
\text { activation }\end{array}$ & 276,8 & IL2, RET, GDNF, SHC1, SHC3, IRS2, LYN, VAV2 & 9.80 & $2.87 \times 10^{-3}$ & Reactome \\
\hline & DAP12 signaling & 330,8 & IL2, RET, GDNF, SHC1, SHC3, IRS2, GSK3A, VAV2 & 8.20 & 0.01 & Reactome \\
\hline \multicolumn{7}{|l|}{ Cell cycle } \\
\hline & $\begin{array}{l}\text { Cyclin A CDK2-associated } \\
\text { events at S phase entry }\end{array}$ & 70,5 & MYC, CDK2, CDC25B, CKS1B, MNAT1 & 24.16 & $4.06 \times 10^{-3}$ & Reactome \\
\hline & G1/S transition & 139,6 & MYC, CKS1B, MNAT1, CDK2, CDC6, CDK6 & 14.6 & $6.73 \times 10^{-3}$ & Reactome \\
\hline \multicolumn{7}{|c|}{$\begin{array}{l}\text { Development/ } \\
\text { growth }\end{array}$} \\
\hline & FGFR signaling & 318,8 & IL2, RET, GDNF, SHC1, SHC3, IRS2, GSK3A, CBL & 8.51 & $8.09 \times 10^{-3}$ & Reactome \\
\hline & Signaling by SCF-KIT & 311,9 & $\begin{array}{l}\text { IL2, RET, GDNF, SHC1, SHC3, IRS2, GSK3A, LYN, } \\
C B L\end{array}$ & 9.79 & $6.14 \times 10^{-4}$ & Reactome \\
\hline & Developmental biology & 806,11 & $\begin{array}{l}\text { VAV2, LYN, HIST2H2BE, HSP9OAA1, IRS2, SHC3, } \\
\text { SHC1, NCOR2M, GDNF, RET, IL2 }\end{array}$ & 4.62 & 0.04 & Reactome \\
\hline & $\begin{array}{l}\text { Platelet-derived growth factor } \\
\text { signaling pathway }\end{array}$ & 149,5 & MYC, SHC1, SHC3, GSK3A, VAV2 & 11.35 & 0.01 & PANTHER \\
\hline
\end{tabular}

Abbreviations: bvFTD = behavioral variant frontotemporal dementia; DAP = DNAX-activation protein; EGF $=$ epidermal growth factor; FCERI $=\mathrm{Fc}$ epsilon receptor; FGFR = fibroblast growth factor receptor; GM-CSF = granulocyte-macrophage colony-stimulating factor; GP VI = Glycoprotein Vl; MAPK = mitogenactivated protein kinase; SCF = stem cell factor; VEGF = vascular endothelial growth factor .

Pathway analysis results are shown. For each broad biological pathway, specific pathways from PANTHER and Reactome databases are provided. In all analyses, the $p$-value presented has been adjusted using the Bonferroni technique, which is the default setting for both PANTHER and Reactome. See table e- 6 (links.IwW.com/NXG/A77) for additional details.

in both pathologic cohorts. Taken together, our results provide evidence that the pathologic heterogeneity seen in bvFTD may occur as the product of multiple dysregulated cellular pathways that converge on specific brain networks across the lifespan. Our findings also contribute to the molecular understanding of selective vulnerability in bvFTD and suggest several potential mechanisms by which genetic variation and gene expression abnormalities increase susceptibility to neurodegenerative diseases like bvFTD. Our analyses suggest that this bvFTD risk gene network may overlap with $\mathrm{AD}$, a related disorder sharing genetic risk factors $^{23}$ and tau pathology ${ }^{24}$ that can also present with a bvFTD-like syndrome. ${ }^{25}$ Additional analyses will be useful to elucidate the specificity of these findings to bvFTD compared with $\mathrm{AD}$ and determine any shared mechanisms conferring risk across other neurodegenerative diseases. 
Table 2 Differentially expressed genes enriched in both FTLD pathologic cohorts

\begin{tabular}{|c|c|c|c|c|c|c|c|c|c|c|c|c|c|c|c|c|c|}
\hline \multirow[b]{3}{*}{$\begin{array}{l}\text { Gene } \\
\text { symbol }\end{array}$} & \multicolumn{6}{|c|}{ Chen-Plotkin et al. ${ }^{21}$} & \multicolumn{6}{|c|}{ Bronner et al. ${ }^{22}$} & \multirow{2}{*}{\multicolumn{4}{|c|}{$\begin{array}{l}\text { Allen et al. }{ }^{16} \text { and Lesnick et al. }{ }^{17} \\
\text { Disease comparisons }\end{array}$}} & \multirow[b]{3}{*}{$\begin{array}{l}\text { Disease } \\
\text { associations }\end{array}$} \\
\hline & \multicolumn{2}{|c|}{ Combined analyses } & \multicolumn{4}{|c|}{ Split by GRN genotype } & \multicolumn{2}{|c|}{ Combined analyses } & \multicolumn{4}{|c|}{ Split by pathologic diagnosis } & & & & & \\
\hline & Bronner & Bronner & $\begin{array}{l}\text { GRN + } \\
\text { Praw }\end{array}$ & $\begin{array}{l}\text { GRN + } \\
\text { PFDR }\end{array}$ & $\begin{array}{l}\text { GRN - } \\
\text { Praw }\end{array}$ & $\begin{array}{l}\text { GRN - } \\
\text { PFDR }_{\text {F }}\end{array}$ & Praw & $P_{\mathrm{FDR}}$ & $\begin{array}{l}\text { Type } \\
\text { C1 Praw }\end{array}$ & $\begin{array}{l}\text { Type } \\
\text { C1 P PDR }\end{array}$ & $\begin{array}{l}\text { Type } \\
\text { A Praw }\end{array}$ & $\begin{array}{l}\text { Type } \\
\text { A P FDR }\end{array}$ & AD $P_{\text {raw }}$ & $A D P_{F D R}$ & $\begin{array}{l}\text { PD } \\
P_{\text {raw }}\end{array}$ & $\begin{array}{l}\text { PD } \\
\text { PFDR }\end{array}$ & \\
\hline BAIAP2 $^{\mathrm{a}}$ & $6.28 \times 10^{-3}$ & 0.03 & 0.56 & 0.65 & $2.35 \times 10^{-4}$ & $2.43 \times 10^{-3}$ & $7.48 \times 10^{-3}$ & 0.05 & 0.02 & 0.45 & 0.08 & 0.32 & $2.75 \times 10^{-6}$ & $8.41 \times 10^{-5}$ & 0.08 & 0.51 & $A D,{ }^{34}$ autism, $A D H D^{35}$ \\
\hline CALD1 & $5.84 \times 10^{-4}$ & 0.01 & $3.64 \times 10^{-4}$ & $7.51 \times 10^{-3}$ & $4.31 \times 10^{-3}$ & 0.02 & $8.78 \times 10^{-3}$ & 0.05 & 0.19 & 0.69 & 0.03 & 0.32 & $1.60 \times 10^{-7}$ & $1.12 \times 10^{-5}$ & 0.05 & 0.36 & $A L S, A D, F T L D^{36}$ \\
\hline$E_{E B B 3^{a}}$ & $3.54 \times 10^{-3}$ & 0.02 & $2.87 \times 10^{-3}$ & 0.02 & 0.02 & 0.06 & $7.50 \times 10^{-3}$ & 0.05 & 0.22 & 0.7 & 0.07 & 0.32 & 0.64 & 0.72 & 0.10 & 0.54 & $\mathrm{PD}^{37}$ \\
\hline GSK3A & $3.20 \times 10^{-4}$ & $9.05 \times 10^{-3}$ & 0.01 & 0.04 & $6.15 \times 10^{-4}$ & $5.08 \times 10^{-3}$ & $2.67 \times 10^{-3}$ & 0.04 & 0.19 & 0.69 & 0.04 & 0.32 & $1.43 \times 10^{-3}$ & $8.53 \times 10^{-3}$ & 0.22 & 0.75 & $\mathrm{FTLD}_{1}^{38} A \mathrm{D}^{39}$ \\
\hline MAPЗК5 & $2.59 \times 10^{-3}$ & 0.02 & $9.20 \times 10^{-3}$ & 0.03 & 0.03 & 0.09 & $3.97 \times 10^{-3}$ & 0.04 & 0.17 & 0.69 & $2.77 \times 10^{-3}$ & 0.14 & $2.77 \times 10^{-6}$ & $8.44 \times 10^{-5}$ & 0.42 & 0.86 & $\begin{array}{l}\text { ALS, FTLD, } \\
\text { Huntington }\end{array}$ \\
\hline POU2F2 ${ }^{\mathrm{a}}$ & $8.51 \times 10^{-4}$ & 0.01 & 0.17 & 0.27 & $7.24 \times 10^{-5}$ & $1.43 \times 10^{-3}$ & $5.68 \times 10^{-5}$ & $4.29 \times 10^{-3}$ & 0.01 & 0.45 & $2.65 \times 10^{-3}$ & 0.14 & $1.07 \times 10^{-3}$ & $6.98 \times 10^{-3}$ & 0.18 & 0.68 & - \\
\hline SMARCA2 ${ }^{\mathrm{a}}$ & $2.63 \times 10^{-3}$ & 0.02 & 0.32 & 0.43 & $1.32 \times 10^{-4}$ & $1.93 \times 10^{-3}$ & $8.90 \times 10^{-3}$ & 0.05 & 0.24 & 0.7 & 0.06 & 0.32 & 0.41 & 0.52 & 0.10 & 0.55 & $\begin{array}{l}\text { Nicolaides-Braitser } \\
\text { syndrome }{ }^{41}\end{array}$ \\
\hline$C D C 37^{\mathrm{a}}$ & 0.01 & 0.05 & $5.31 \times 10^{-4}$ & $7.51 \times 10^{-3}$ & 0.19 & 0.33 & $4.83 \times 10^{-5}$ & $4.29 \times 10^{-3}$ & $2.97 \times 10^{-3}$ & 0.45 & 0.01 & 0.31 & $2.28 \times 10^{-3}$ & 0.01 & 0.61 & 0.91 & $A D^{42}$ \\
\hline TGFB1/1 & $8.84 \times 10^{-3}$ & 0.04 & $1.37 \times 10^{-3}$ & 0.01 & 0.08 & 0.18 & $6.79 \times 10^{-3}$ & 0.05 & 0.11 & 0.68 & $5.09 \times 10^{-3}$ & 0.19 & $2.85 \times 10^{-3}$ & 0.01 & 0.87 & 0.96 & $\mathrm{AD}^{43} \mathrm{FTD}^{44}$ \\
\hline
\end{tabular}

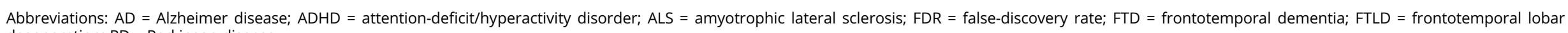
degeneration; $P D=$ Parkinson disease.

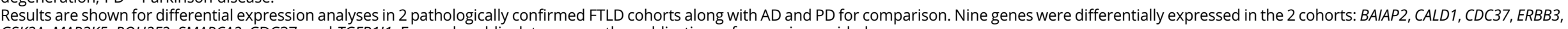

GSK3A, MAP3K5, POU2F2, SMARCA2, CDC37, and TGFB1/1. For each public data source, the publication reference is provided.
a Indicates to the best of our knowledge not previously reported in FTLD. 
By integrating GWAS with protein interaction data, gene expression data from across the lifespan, and postmortem gene expression data from confirmed FTLD cases, we highlight the importance of bvFTD risk genes during development, aging, and disease. Our network genes showed enrichment in regions of the brain commonly affected in bvFTD such as the dorsolateral and ventrolateral prefrontal cortices, and inferior temporal cortex (figure 3). Because of the scarcity of pathologic samples available for enrichment analyses, some regions of the brain that have known roles in bvFTD, such as the cingulate and insula, were not available for analysis. Of interest, our genes also showed enrichment in brain regions typically spared in bvFTD patients such as superior temporal cortex, occipital cortex, and sensory cortex. Although the reason for this enrichment remains to be determined, it is possible that spared regions contain similar cell types as vulnerable ones but remain unaffected because they are functionally disconnected from pathologically affected regions in bvFTD and remain unexposed to pathologic aggregates that may disseminate through functionally connected neural networks. ${ }^{26,27}$ Alternatively, and perhaps counterintuitively, consistently enriched expression (and thereby greater expression across the lifespan) of bvFTD network genes in regions like cerebellum and superior temporal cortex could potentially provide protection against neurodegenerative processes. In this framework, reduced expression of the same genes in other, less-enriched, brain regions may result in vulnerability to disease pathology because less-enriched brain regions have less "reserve" expression to rely on during aging, potentially reducing the threshold within which variable expression is tolerated by relevant biological systems.

An exploratory analysis revealed that our bvFTD network genes are most highly expressed in fetal astrocytes, neurons, and microglia/macrophages. The importance of fetal astrocytes is particularly interesting in the context of our pathway findings as they are implicated in neurodevelopmental processes, complement signaling, and forming healthy neuronal synapses. ${ }^{28}$ Many of the identified bvFTD risk genes were most highly expressed in neuronal populations, which participate in many of the cell signaling pathways highlighted in our GO analyses. ${ }^{29}$ Neurons may also be the target of abnormal expression of cell-cycle regulation proteins, which have been shown in studies of neurodegenerative diseases to result in apoptosis when activated. ${ }^{30,31}$ The third major cell type expressing our genes of interest-microglia/ macrophages - play an increasingly appreciated role in the pathogenesis of bvFTD and other neurodegenerative disorders. ${ }^{32}$ Remarkably, our CSEA analyses highlighted layer $5 \mathrm{~b}$ cortical neurons as sites of bvFTD network gene expression enrichment. Pathologic evidence in human brain tissue suggests this cortical layer as a likely site of selectively vulnerable neuronal populations in bvFTD (VENs and fork cells). ${ }^{33}$ While this finding was not significant after correction for multiple testing, it is striking for its convergence on the site of bvFTD neurodegeneration in the cortex and provides a strong impetus for further study of bvFTD risk gene expression patterns in these specific cell populations.

Limitations of this study include lack of a suitable case-control data set of sufficient size to confirm whether our network and risk loci are associated with disease risk and lack of access to raw IFGC genotype data to perform subgroup analyses. Phase III data of the IFGC (on over 2,000 new cases) will be released in the near future and that cohort could represent a suitable cohort for validation of these findings and further characterization efforts. Our data-sharing agreement with the IFGC provided SNP-level GWAS results only and we did not have raw genetic data, which precludes potentially more powerful study designs, such as subsetting the cohort into training and testing data sets. Beyond this, our network generation methodology relies on already existing protein interaction data and thus could bias our ontological findings toward more thoroughly characterized biological pathways and processes. An additional limitation of our gene expression analyses stems from Constantinidis diagnoses, which are not easily converted into more modern pathologic diagnoses.

In our analyses, we identified and bioinformatically characterized a gene network linked at the protein level that shows enriched expression across the human lifespan in brain areas most affected by bvFTD and shows dysregulation in pathologically diagnosed FTLD cases. These findings suggest that multiple distinct biological pathways are altered in sporadic bvFTD, including signal transduction, cell cycle regulation, immune/inflammation, and neurodevelopmental processes. Together, these pathway enrichments raise an important and unanswered question regarding the temporal relationship between genetic variation and biological risk for disease. It is plausible that a subset of risk variants promotes disease risk specifically during development, while others promote risk through nuanced changes in biological function in aging. It is also possible that genetic variation may be helpful during development but detrimental during aging if activated inappropriately (e.g., synaptic pruning by the innate immune system). Future longitudinal studies of at-risk individuals will be required to fully address this question. Although no single genetic variant used to generate our network directly causes bvFTD, the cumulative burden of multiple sub-GWASassociated variants within these pathways may alter the cellular landscape on which development and aging occurs, thereby altering the amount of metabolic stress, inflammation, and apoptotic tendencies of particular cell types in defined brain networks. Our results support the utility of polygenic scores that incorporate the effects of multiple genetic loci for clinical risk assessment and prevention study enrichment, and genetic overlap with $\mathrm{AD}$ suggests shared underlying biology across multiple neurodegenerative disorders. Understanding the temporal tropism of these risk factors on disease vulnerability will also be critical for translating these results into therapeutic targets for clinical populations, especially for processes such as metabolic stress and immune dysfunction that are more amenable to intervention. If confirmed, our 
findings represent a valuable step toward a genetic understanding of selective vulnerability in neurodegenerative disease.

\section{Authors contributions}

L.W. Bonham: design and conceptualization of the study, analysis and interpretation of the data, drafting and revising the manuscript for intellectual content. N.Z.R. Steele: analysis and interpretation of the data, drafting and revising the manuscript for intellectual content. C.M. Karch: analysis and interpretation of the data, revising the manuscript for intellectual content. C. Manzoni: interpretation of the data, revising the manuscript for intellectual content. E.G. Geier: interpretation of the data, revising the manuscript for intellectual content. N. Wen, interpretation of the data, revising the manuscript for intellectual content. A. Ofori-Kuragu: analysis and interpretation of the data, revising the manuscript for intellectual content. P. Momeni: design and conceptualization of the study, revising the manuscript for intellectual content. J. Hardy: design and conceptualization of the study, revising the manuscript for intellectual content. Z.A. Miller: design and conceptualization of the study, revising the manuscript for intellectual content. C.P. Hess: design and conceptualization of the study, revising the manuscript for intellectual content. P. Lewis: design and conceptualization of the study, revising the manuscript for intellectual content. B.L. Miller: design and conceptualization of the study, revising the manuscript for intellectual content. W.W. Seeley: design and conceptualization of the study, interpretation of the data, revising the manuscript for intellectual content. S.E. Baranzini: design and conceptualization of the study, interpretation of the data, revising the manuscript for intellectual content. R.S. Desikan: design and conceptualization of the study, interpretation of the data, revising the manuscript for intellectual content. R. Ferrari: design and conceptualization of the study, analysis and interpretation of the data, revising the manuscript for intellectual content. J.S. Yokoyama: design and conceptualization of the study, analysis and interpretation of the data, drafting and revising the manuscript for intellectual content.

\section{Acknowledgment}

The authors thank the International FTD-Genomics Consortium (IFGC) for providing phase I summary statistics data for these analyses. IFGC acknowledgements and full collaborator list are provided in appendix e-1 (links.lww. com/NXG/A71).

\section{Study funding}

Primary support for data analyses was provided by the Radiologic Society of North America (RSNA) RMS1741 (L.W.B.), Larry L. Hillblom Foundation 2012-A-015-FEL and 2016-A-005-SUP (J.S.Y.), AFTD Susan Marcus Memorial Fund Clinical Research Grant (J.S.Y.), NIA K01 AG049152 (J.S.Y.), Bluefield Project to Cure FTD (J.S.Y.), Tau Consortium (J.S.Y.), NIA K01 AG046374 (C.M.K.), U24DA041123 (R.S.D.), National Alzheimer's Coordinating
Center (NACC) Junior Investigator Award (R.S.D.), RSNA Resident/Fellow Grant (R.S.D.), Foundation of ASNR Alzheimer's Imaging Grant (R.S.D.), and Alzheimer's Society Grant 284 (R.F.). Additional support was provided by an MRC Programme grant (MR/N026004/1; J.H. and P.A.L.), NIA P01 AG1972403 (B.L.M.), NIA P50 AG023501 (B.L.M.), and a MRC New Investigator Research Grant (MR/L010933/1; P.A.L.). P.A. Lewis is a Parkinson's UK research fellow (grant F1002). The funders had no role in study design, data collection and analysis, decision to publish, or preparation of the manuscript.

\section{Disclosure}

L.W. Bonham has received research support from the Radiologic Society of North America. N.Z.R. Steele, C.M. Karch, N. Wen, A. Ofori-Kuragu, P. Momeni report no disclosures. C. Manzoni has received a bursary from NIH; serves on the editorial board of Frontiers; and has receives research support/ salary from the Medical Research Council. E.G. Geier holds a patent (pending) for Targeted platinum anticancer agents. J. Hardy has served on scientific advisory boards for Eisai and Lilly; has been a consultant for Eisai and Ceracuity; and has received research support from the Medical Research Council. Z.A. Miller holds patents for Dynamic and adjustable portable X-ray filter grid and Dynamic and adjustable filter grids; and has received research support from NIH. C.P. Hess serves on the editorial boards of the American Journal of Neuroradiology and PLoS One; has been a consultant for Imaging Endpoints; has received research support from General Electric and NIH; and has provided expert witness for various legal trials. P. Lewis has received travel funding from the Biochemical Society; serves on the editorial boards of Biology Direct, PLoS One, and Frontiers in Neurodegenerative Disease; and has received research support from the Medical Research Council, the Biotechnology and Biological Sciences Research Council, Diamond Light Source, and Parkinson's UK. B.L. Miller has served on the scientific advisory boards of the Tau Consortium, the John Douglas French Foundation, the Larry L. Hillblom Foundation, the Consortium for Frontotemporal Dementia Research, the Global Brain Health Institute (GBHI), University of Washington ADRC, Stanford University ADRC, the Arizona Alzheimer's Disease Center (ADC), the Massachusetts Alzheimer Disease Research Center, and the International Society of FTD; has served on the editorial boards of Cambridge University Press, Guilford Publications Inc, Oxford University Press, Neurocase, Elsevier, Up-To-Date, and Frontiers; receives publishing royalties from Cambridge University Press, Elsevier, Guilford Publications, and Oxford University Press; and has received research support from Quest Diagnostics Incorporated, and NIA. W.W. Seeley serves on the editorial boards of Annals of Neurology, Acta Neuropathologica, and Neuroimage: Clinical; has been a consultant for Bristol-Myers Squibb, Merck, and Biogen Idec; has received research support from NIH; and has provided expert witness for a defendant. S.E. Baranzini has served on scientific advisory boards for Novartis, EMD Serono, and Sanofi-Aventis; has received gifts, travel funding, and speaker 
honoraria from Novartis; serves on the editorial board of the Multiple Sclerosis Journal; holds a patent (pending) for a gene expression signature that could identify patients at high risk of developing multiple sclerosis; has been a consultant for Novartis, EMD Serono, and TEVA Neuroscience; and has received research support from $\mathrm{NIH}$, the Department of Defense, and NMSS. R.S. Desikan has received research support from NIH, the National Alzheimer's Coordinating Center (NACC) Junior Investigator Award, RSNA, and the Foundation of ASNR. R. Ferrari has received travel funding/ registration fee reimbursement from Sindem4Juniors and the Alzheimer's Association International Conference; and has received research support from the Alzheimer's Society. J.S. Yokoyama has served on the editorial boards of the Journal of Alzheimer's Disease and Frontiers in Neurology; and has received research support from Quest Diagnostics, NIH, the Association for Frontotemporal Degeneration, the Larry L. Hillblom Foundation, the Rainwater Charitable Foundation, the John Douglas French Alzheimer's Foundation, and the Bluefield Project to Cure FTD. Full disclosure form information provided by the authors is available with the full text of this article at Neurology.org/NG.

Received January 29, 2018. Accepted in final form July 31, 2018.

\section{References}

1. Seeley WW, Crawford RK, Zhou J, Miller BL, Greicius MD. Neurodegenerative diseases target large-scale human brain networks. Neuron 2009;62:42-52.

2. Warren JD, Rohrer JD, Schott JM, Fox NC, Hardy J, Rossor MN. Molecular nexopathies: a new paradigm of neurodegenerative disease. Trends Neurosci 2013:561-569.

3. Zhou J, Gennatas ED, Kramer JH, Miller BL, Seeley WW. Predicting regional neurodegeneration from the healthy brain functional connectome. Neuron 2012;73: 1216-1227.

4. Boyle EA, Li YI, Pritchard JK. An expanded view of complex traits: from polygenic to omnigenic. Cell 2017;169:1177-1186.

5. Baranzini S, Khankhanian P, Patsopoulos N, et al. Network-based multiple sclerosis pathway analysis with GWAS data from 15,000 cases and 30,000 controls. Am J Hum Genet 2013;92:854-865.

6. Wang C, Ji F, Hong Z, et al Disrupted salience network functional connectivity and white-matter microstructure in persons at risk for psychosis: findings from the LYRIKS study. Psychol Med 2016;46:2771-2783.

7. Rascovsky K, Hodges JR, Kipps CM, et al. Diagnostic criteria for the behavioral variant of frontotemporal dementia (bvFTD): current limitations and future directions. Alzheimer Dis Assoc Disord 2007;21:S14-S18.

8. Ferrari R, Hernandez DG, Nalls MA, et al. Frontotemporal dementia and its subtypes: a genome-wide association study. Lancet Neurol 2014;13:686-699.

9. Liu JZ, McRae AF, Nyholt DR, et al. A versatile gene-based test for genome-wide association studies. Am J Hum Genet 2010;87:139-145.

10. Frazer KA, Ballinger DG, Cox DR; The International HapMap Corsortium. A second generation human haplotype map of over 3.1 million SNPs. Nature 2007;449: $851-861$.

11. Ferrari R, Lovering RC, Hardy J, Lewis PA, Manzoni C. Weighted protein interaction network analysis of frontotemporal dementia. J Proteome Res 2017;16: 999-1013.

12. Zhang Y, Sloan SA, Clarke LE, et al. Purification and characterization of progenitor and mature human astrocytes reveals transcriptional and functional differences with mouse. Neuron 2016;89:37-53.

13. Sheng J, Su L, Xu Z, Chen G. Progranulin polymorphism rs5848 is associated with increased risk of Alzheimer's disease. Gene 2014;542:141-145.

14. Schmidt EF, Warner-Schmidt JL, Otopalik BG, Pickett SB, Greengard P, Heintz N. Identification of the cortical neurons that mediate antidepressant responses. Cell 2012;149:1152-1163.

15. Reimand J, Arak T, Adler P, et al. g:Profiler: a web server for functional interpretation of gene lists (2016 update). Nucleic Acids Res 2016;44:W83-W89.
16. Allen M, Carrasquillo MM, Funk $\mathrm{C}$, et al. Human whole genome genotype and transcriptome data for Alzheimer's and other neurodegenerative diseases. Sci data 2016;3:160089.

17. Lesnick TG, Papapetropoulos S, Mash DC, et al. A genomic pathway approach to a complex disease: axon guidance and Parkinson disease. PLoS Genet 2007;3: 0984-0995.

18. Kang HJ, Kawasawa YI, Cheng F, et al. Spatio-temporal transcriptome of the human brain. Nature 2011;478:483-489.

19. Bennett ML, Bennett FC, Liddelow SA, et al. New tools for studying microglia in the mouse and human CNS. Proc Natl Acad Sci 2016;113:E1738-E1746.

20. Dijkstra AA, Lin LC, Nana AL, Gaus SE, Seeley WW. Von economo neurons and fork cells: a neurochemical signature linked to monoaminergic function. Cereb Cortex 2016;45:846-860.

21. Chen-Plotkin AS, Geser F, Plotkin JB, et al. Variations in the progranulin gene affect global gene expression in frontotemporal lobar degeneration. Hum Mol Genet 2008; 17:1349-1362.

22. Bronner IF, Bochdanovits Z, Rizzu P, et al. Comprehensive mRNA expression profiling distinguishes tauopathies and identifies shared molecular pathways. PLOS ONE 2009;4:e6826.

23. Ferrari R, Wang Y, Vandrovcova J, et al. Genetic architecture of sporadic frontotemporal dementia and overlap with Alzheimer's and Parkinson's diseases. J Neurol Neurosurg Psychiatry 2017;88:152-164.

24. Iqbal K, Liu F, Gong CX. Tau and neurodegenerative disease: the story so far. Nat Rev Neurol 2015;12:15-27.

25. Sawyer RP, Rodriguez-Porcel F, Hagen M, Shatz R, Espay AJ. Diagnosing the frontal variant of Alzheimer's disease: a clinician's yellow brick road. J Clin Mov Disord 2017;4:2.

26. Brettschneider J, Del Tredici K, Lee VM, Trojanowski JQ. Spreading of pathology in neurodegenerative diseases: a focus on human studies. Nat Rev Neurosci 2015;16: $109-120$.

27. Cohen TJ, Lee VM, Trojanowski JQ. TDP-43 functions and pathogenic mechanisms implicated in TDP-43 proteinopathies. Trends Mol Med 2011;17:659-667.

28. Yang Y, Higashimori H, Morel L. Developmental maturation of astrocytes and pathogenesis of neurodevelopmental disorders. J Neurodev Disord 2013;5:22.

29. Ferrari R, Wang Y, Vandrovcova J, et al. Genetic architecture of sporadic frontotemporal dementia and overlap with Alzheimer's and Parkinson's diseases. J Neurol Neurosurg Psychiatry 2017;88:152-164.

30. Becker EB, Bonni A. Cell cycle regulation of neuronal apoptosis in development and disease. ProgNeurobiol 2004;72:1-25.

31. Copani A, Caraci F, Hoozemans JJM, Calafiore M, Angela Sortino M, Nicoletti F. The nature of the cell cycle in neurons: focus on a "non-canonical" pathway of DNA replication causally related to death. Biochim Biophys Acta 2007;1772:409-412.

32. Minami SS, Min SW, Krabbe G, et al. Progranulin protects against amyloid $\beta$ deposition and toxicity in Alzheimer's disease mouse models. Nat Med 2014;20: $1157-1164$

33. Santillo AF, Englund E. Greater loss of von Economo neurons than loss of layer II and III neurons in behavioral variant frontotemporal dementia. Am J Neurodegener Dis 2014;3:64-71.

34. Chow F, Gong Y, Lippa CF. The potential role of insulin on the shank-postsynaptic platform in neurodegenerative diseases involving cognition. Am J Alzheimer's Dis Other Demen 2014;29:303-310.

35. Kang J, Park H, Kim E. IRSp53/BAIAP2 in dendritic spine development, NMDA receptor regulation, and psychiatric disorders. Neuropharmacology 2016;100:27-39.

36. Narayanan RK, Mangelsdorf M, Panwar A, Butler TJ, Noakes PG, Wallace RH. Identification of RNA bound to the TDP-43 ribonucleoprotein complex in the adult mouse brain. Amyotroph Lateral Scler Front Degener 2013;14:252-260.

37. Lue LF, Schmitz CT, Snyder NL, et al. Converging mediators from immune and trophic pathways to identify Parkinson disease dementia. Neurol Neuroimmunol Neuroinflamm 2016;3:e193.

38. Hooper C, Killick R, Lovestone S. The GSK3 hypothesis of Alzheimer's disease. J Neurochem 2008;104:1433-1439.

39. Trojanowski JQ Duff K, Fillit $\mathrm{H}$, et al. New directions for frontotemporal dementia drug discovery. Alzheimers Dement 2008;4:89-93.

40. Sekine Y, Takeda K, Ichijo H. The ASK1-MAP kinase signaling in ER stress and neurodegenerative diseases. Curr Mol Med 2006;6:87-97.

41. Sousa SB, Hennekam RC, Abdul-Rahman O, et al. Phenotype and genotype in Nicolaides-Baraitser syndrome. Am J Med Genet C Semin Med Genet 2014;166: 302-314.

42. Zhang YJ, Gendron TF, Xu YF, Ko LW, Yen SH, Petrucelli L. Phosphorylation regulates proteasomal-mediated degradation and solubility of TAR DNA binding protein-43 C-terminal fragments. Mol Neurodegener 2010;5:1-13.

43. Moradifard S, Hoseinbeyki M, Ganji SM, Minuchehr Z. Analysis of microRNA and gene expression profiles in Alzheimer's disease: a meta-analysis approach. Sci Rep 2018;8:4767.

44. Dobson-Stone C, Luty AA, Thompson EM, et al. Frontotemporal dementiaamyotrophic lateral sclerosis syndrome locus on chromosome 16p12.1-q12.2: genetic, clinical and neuropathological analysis. Acta Neuropathol 2013;125:523-533. 


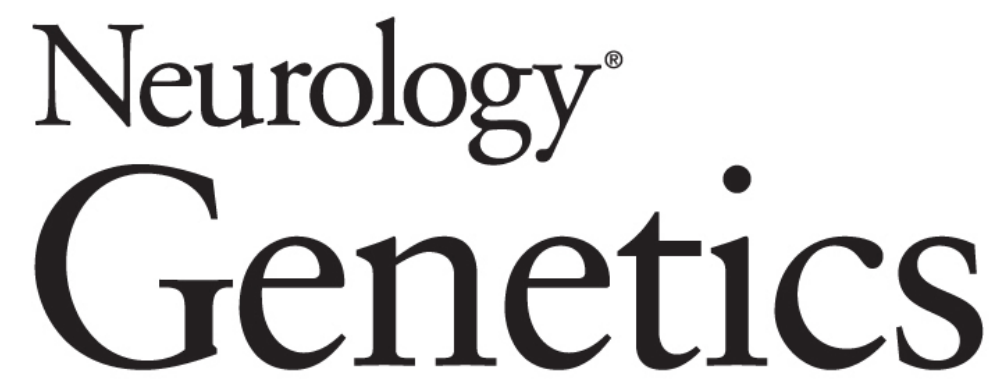

Protein network analysis reveals selectively vulnerable regions and biological processes in FTD

Luke W. Bonham, Natasha Z.R. Steele, Celeste M. Karch, et al. Neurol Genet 2018;4;

DOI 10.1212/NXG.0000000000000266

This information is current as of October 1, 2018

Neurol Genet is an official journal of the American Academy of Neurology. Published since April 2015, it is an open-access, online-only, continuous publication journal. Copyright Copyright ( 2018 The Author(s).

Published by Wolters Kluwer Health, Inc. on behalf of the American Academy of Neurology.. All rights reserved. Online ISSN: 2376-7839.

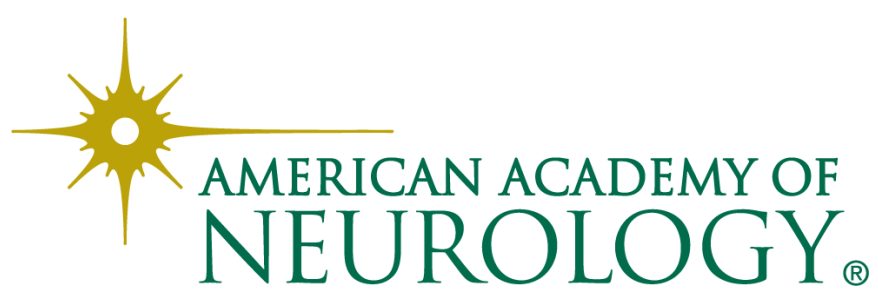




\section{Updated Information \& Services}

References

Citations

Subspecialty Collections

Permissions \& Licensing

Reprints including high resolution figures, can be found at: http://ng.neurology.org/content/4/5/e266.full.html

This article cites 43 articles, 3 of which you can access for free at: http://ng.neurology.org/content/4/5/e266.full.html\#\#ref-list-1

This article has been cited by 2 HighWire-hosted articles: http://ng.neurology.org/content/4/5/e266.full.html\#\#otherarticles

This article, along with others on similar topics, appears in the following collection(s):

\section{All Cognitive Disorders/Dementia}

http://ng.neurology.org//cgi/collection/all_cognitive_disorders_dementi a

All Genetics

http://ng.neurology.org//cgi/collection/all_genetics

Association studies in genetics

http://ng.neurology.org//cgi/collection/association_studies_in_genetics Frontotemporal dementia

http://ng.neurology.org//cgi/collection/frontotemporal_dementia

Gene expression studies

http://ng.neurology.org//cgi/collection/gene_expression_studies

Information about reproducing this article in parts (figures,tables) or in its entirety can be found online at:

http://ng.neurology.org/misc/about.xhtml\#permissions

Information about ordering reprints can be found online:

http://ng.neurology.org/misc/addir.xhtml\#reprintsus

Neurol Genet is an official journal of the American Academy of Neurology. Published since April 2015, it is an open-access, online-only, continuous publication journal. Copyright Copyright $\odot 2018$ The Author(s). Published by Wolters Kluwer Health, Inc. on behalf of the American Academy of Neurology.. All rights reserved. Online ISSN: 2376-7839.

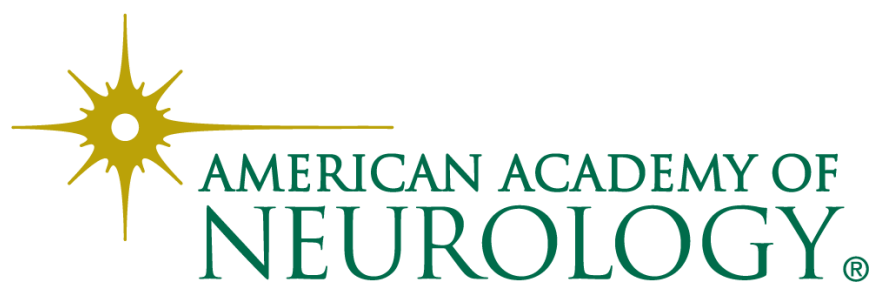

